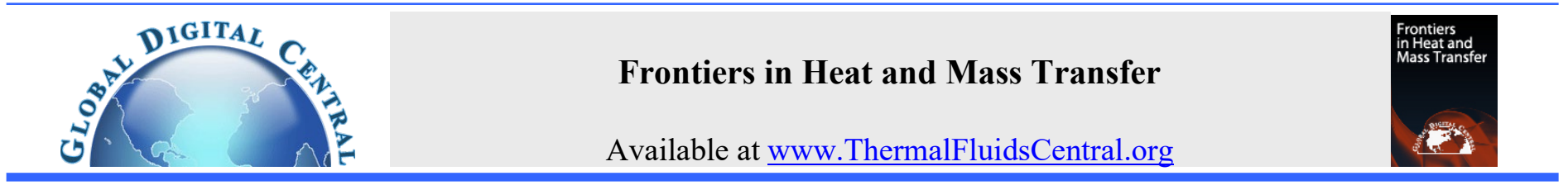

\title{
NUMERICAL INVESTIGATION ON THE THERMAL PERFORMANCE OF A CASCADED LATENT HEAT THERMAL ENERGY STORAGE
}

\author{
Pengda Li, Chao Xu, Zhirong Liao*, Xing Ju, Feng Ye \\ Key Laboratory of Power Station Energy Transfer Conversion and System of MOE, North China Electric Power University, Beijing, 102206, China
}

\begin{abstract}
This study numerically investigates the charging and discharging processes of a three-stages cascaded latent heat thermal energy storage unit using three molten salts as the phase change materials (PCMs). Each stage of the unit is a vertical shell-and-tube heat exchanger, whose shell side is filled with the PCM and air. The liquid fractions, temperatures, and accumulated thermal energy of the PCMs during the fully charging and discharging processes, as well as the effects of the HTF inlet temperature, are analyzed. The results show that lower melting temperature of the PCM causes faster charging rate and more released heat in the cascaded LHTES system. Compared with the non-cascaded LHTES systems, the cascaded LHTES systems can possess better flexibility via the selection of the PCMs.
\end{abstract}

Keywords: latent heat thermal energy storage, cascaded, phase change materials, shell-and-tube heat exchanger, numerical simulation.

\section{INTRODUCTION}

In the last few decades, renewable energy is considered to be one kind of the most effective solution to the energy demand and the environmental problems caused by traditional fossil energy (Lefebvre and Tezel, 2017; Kalogirou, 2004). As one kind of the renewable energy, solar energy is regarded as one promising alternative (Alva et al., 2017; Vyshak and Jilani, 2007). Among the various technologies for the utilization of solar energy, concentrated solar power (CSP) has attracted extensive attention due to its renewability and schedulability (Koberle et al., 2015; Denholm and Mehos, 2011; Sioshansi and Denholm, 2010). More importantly, CSP plants can easily integrate with thermal energy storage (TES), which greatly enhances their flexibility and competition. (Sioshansi and Denholm, 2010; Kuravi et al., 2013).

Generally, TES can be categorized into sensible heat thermal energy storage, latent heat thermal energy storage (LHTES), and thermochemical energy storage (Nkwetta, 2014). Among these, LHTES has favored because of its approximately constant temperature during the melting and solidification processes (Shabgard and Faghri, 2019) and the high thermal energy storage density, which contributes to smaller system volume and lower cost (Hosseini and Rahimi, 2014). However, phase change materials (PCMs) generally have low thermal conductivity, which limits the heat transfer rate and thermal efficiency of LHTES systems (Mosaffa et al., 2013; Xu and Zhao, 2016, 2017). To overcome this disadvantage, scholars have made significant effort to enhance the heat transfer rate, including (1) synthesizing composite phase change materials with high thermal conductivity (Cui et al., 2011; Zhang et al., 2017; Acem et al., 2010); (2) expanding the heat transfer areas, such as adding fins (Ndlovu and Moitsheki, 2019; Hosseini et al., 2015; Al-Abidi et al., 2013); (3) using heat pipes (Shabgard et al., 2010; Singh et al., 2019; Orr, 2019); and (4) using cascaded PCMs. Especially, the cascaded LHTES system can uniform the temperature difference between HTF and PCMs and achieve a high heat transfer rate $\mathrm{Xu}$ et al., 2016). Thus, the cascaded LHTES system shows great potential in applications such as solar thermal utilization, industrial waste heat recovery, building energy saving, and electronic equipment thermal management.

Liu et al. (2015) numerically proved that the increase in the amount of PCMs in series to improve the released efficiency of sensible heat. Domafiski and Fellah (1996) concluded that from the perspective of the second law of thermodynamics, the exergy efficiency could be improved by using multistage PCMs. Shabgard et al. (2012) established a thermal network model for predicting the performance of the LHTES systems containing the multistage PCMs and embedded heat pipes. The results showed that the cascaded LHTES system recovered $10 \%$ more exergy in a $24 \mathrm{~h}$ charging-discharging cycle than the non-cascaded LHTES systems. Li et al. (2013) developed a two-dimensional mathematical model for a shell-and-tube LHTES system with threestage PCMs based on the enthalpy method. The results showed that the third-stage PCM possesses the fastest melting rate, while the first-stage PCM was the slowest in both axial and radial directions. Besides, the melting time of the first-stage PCM experienced the greatest decline with the increase of the HTF inlet temperature. Seeniraj and Narasimhan (2008) simulated the overall impact of utilization multistage PCMs with adding fins. The results showed that the melting rate of the PCMs increases significantly, and the output temperature tends to be uniform in the cascaded LHTES systems. Aldoss and Rahman (2014) filled spherical capsules with multiple PCMs that owned different thermophysical properties. The capsules were arranged in different parts of the bed according to the melting temperature. The results showed that the increase in the number of PCMs could improve the performance of the bed. However, the improvement was not significant when the number of stages reached more than three. Ezra et al. (2016) used a mathematical model to analyze the LHTES units of multi-PCMs arranged in cascade and defined generalized dimensionless parameters applicable to different working conditions, which was used to optimize the design parameters of LHTES systems. The results revealed that the theoretical limit of improvement of multistage PCMs is higher than single PCM's under the same configuration. Wu et al. (2016) presented a transient, one-dimensional dispersion-concentric

\footnotetext{
* Corresponding Author. Email: zhirong.liao@ncepu.edu.cn
} 
model to investigate the dynamic behaviors of the charging and discharging cyclic processes of the molten-salt packed-bed TES system filled with cascaded phase change material (PCM) capsules. The results showed that the cascaded systems had a faster charging and discharging rates, and the threshold temperatures to stop the charging/discharging process determines the practical storage capacity of the storage system.

Peiro et al. (2015) conducted an experimental study on the TES system with two-stage PCMs. The experimental results showed that the temperature difference between the inlet and outlet of the HTF with multistage PCMs is more uniform, and the average efficiency is increased by $19.36 \%$ compared with the one-stage PCM. Michels and Pitz-Paal (2007) carried out experimental research on the cascaded vertical shell-and-tube heat exchangers. The results showed that the heat storage capacity of the LHTES is higher than that of the sensible TES with the same quality of the storage medium. The energy utilization ratio of the cascaded LHTES system reached $57.2 \%$, which was higher than that of the non-cascaded TES systems. Chinnapandian et al. (2015) built a cascade storage system for the waste heat recovery based on the finned shell-and-tube heat exchangers and performed an integrated test with a $7.4 \mathrm{~kW}$ diesel engine. The results showed that about $11 \%-20 \%$ of the heat is recovered with the cascaded storage system, while it is about $10 \%-15 \%$ for the non-cascaded storage system. Yuan et al. (2018) set up a high-temperature experimental bench of the cascaded LHTES with molten salt. The experimental results showed that compared with the non-cascaded system, the total heat storage and the release capacities of the cascaded system could be increased by $39.51 \%$ and $35.74 \%$, respectively. Moreover, the average charging and discharging power were enhanced by $38.40 \%$ and $27.02 \%$, respectively.

In real applications, considering the expansion of PCM, about 80$85 \%$ of the heat storage unit is filled with PCM. Most of the numerical studies mentioned above assume that the heat storage unit is filled with PCM and ignore the volume for expansion. Thus, all of the container shells are direct contact with the PCM. However, such an assumption quite differs from the practical situation, where the top of the heat storage unit exchanges heat with air instead of the PCM. Thus, the obtained heat transfer at the top of the unit is calculated with some certain inaccuracy. Moreover, there are few researches that independently simulate each single stage of the cascaded LHTES system.

This study investigates the melting and solidification performance of a lab-scale storage unit with cascaded PCMs. More importantly, the air at the top of the storage unit is considered to make the numerical model more authentic and reliable. Also, three shell-and-tube components and PCMs in the LHTES unit are numerically simulated simultaneously. Firstly, the lab-scale cascaded LHTES unit is proposed, and a numerical model is developed. After validation, the model is used to simulate the fully charging and discharging processes of the proposed LHTES unit. Meanwhile, the dynamical thermal performance of the charging and discharging processes is analyzed. The evolutions of liquid fraction, temperature, and heat transfer amount of the threestages PCMs are discussed. Moreover, the effects of the HTF inlet temperature on heat transfer of the cascaded system are studied. The findings of the present study are helpful for the design of a cascaded LHTES unit.

\section{NUMERICAL SIMULATION}

\subsection{Physical Model}

Figure 1 shows the schematic diagram of a lab-scale three-stages LHTES unit. Each stage is a vertical shell-and-tube heat exchanger where PCM is filled in the shell side. During the charging process, the HTF flows through Value 1, Stage 1, Stage 2, Stage 3, Values 4 and 5 in succession; while during the discharging process, the HTF flows through Values 2 and 4, Stage 3, Stage 2, Stage 1, and Value 3 in turn. The PCM of Stage 1 (PCM1) has the highest melting point, then PCM 2
(Stage 2), and then PCM3 (Stage 3). Such arrangement can approximately maintain constant heat transfer temperature difference so as to keep constant and high charging and discharging powers (Yuan et al.,2017). Due to the axisymmetric structure, each heat exchanger can be simplified into a two-dimensional physical model. Then, as shown in Fig. 2, the physical model of the LHTES unit can be simplified as three heat exchangers connected to each other. The heat exchangers are made of stainless steel, and their sizes are listed in Table 1. The heat exchangers are wrapped up by the glass wool with a thickness of 250 $\mathrm{mm}$ to reduce the heat loss.

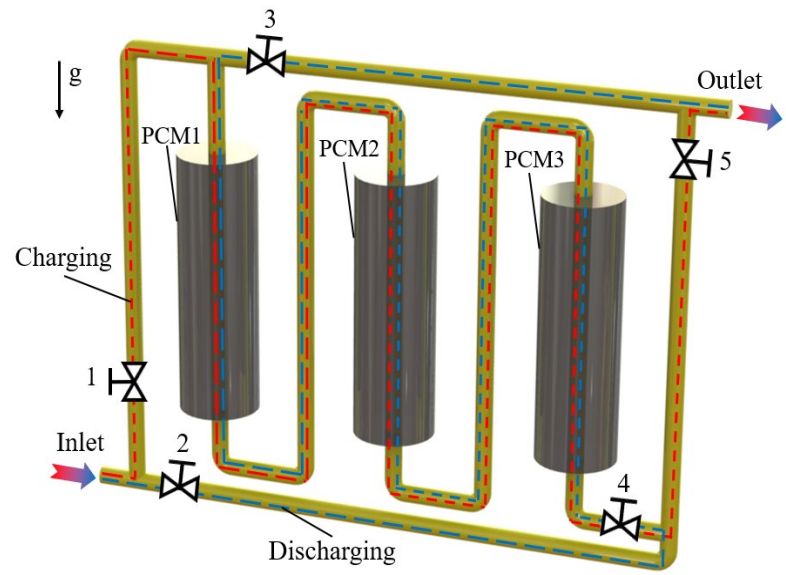

Fig. 1 Schematic diagram of the LHTES unit

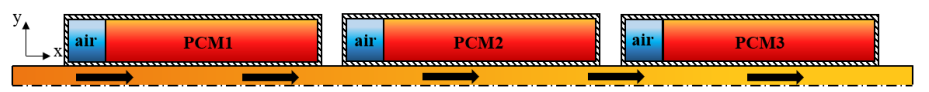

Fig. 2 Physical model of the LHTES unit

Table 1 Geometric parameters of the LHTES unit.

\begin{tabular}{|c|c|}
\hline Parameters & Values (mm) \\
\hline Shell inner diameter & 60 \\
\hline Shell inner length & 400 \\
\hline Shell thickness & 5 \\
\hline Shell outer length & 410 \\
\hline Tube inner diameter & 12.5 \\
\hline Tube thickness & 1.5 \\
\hline Insulation thickness & 250 \\
\hline
\end{tabular}

Table 2 Thermophysical properties of PCMs (Serrano-López et al., 2013; Omotani and Nagashima, 1984; Iverson et al., 2012; Zhou and Eames, 2016).

\begin{tabular}{|c|c|c|c|}
\hline $\begin{array}{c}\text { Thermophysical } \\
\text { properties }\end{array}$ & PCM1 & PCM2 & PCM3 \\
\hline$T_{s}(\mathrm{~K})$ & 494.15 & 463.75 & 415.59 \\
\hline$T_{l}(\mathrm{~K})$ & 509.15 & 475.85 & 423.25 \\
\hline$L(\mathrm{~J} / \mathrm{g})$ & 102.1 & 250.1 & 51.63 \\
\hline \multirow{2}{*}{$\lambda(\mathrm{W} / \mathrm{m} \cdot \mathrm{K})$} & $0.76(\mathrm{~s})$ & $0.74(\mathrm{~s})$ & $0.99(\mathrm{~s})$ \\
\hline & $0.45(1)$ & $0.48(1)$ & $0.56(1)$ \\
\hline$c_{p}(\mathrm{~J} / \mathrm{kg} \cdot \mathrm{K})$ & $\begin{array}{l}399.33+ \\
2.1934 \mathrm{~T}\end{array}$ & $\begin{array}{c}890.3234+1.564 \mathrm{~T}(\mathrm{~s}) \\
-14195.743+60.478 \mathrm{~T}- \\
0.05579 \mathrm{~T}^{2}(1)\end{array}$ & $\begin{array}{l}291.33+ \\
2.6618 T\end{array}$ \\
\hline$\rho\left(\mathrm{kg} / \mathrm{m}^{3}\right)$ & 2074 & 1994 & 2061 \\
\hline
\end{tabular}

Table 3 Thermophysical properties of HTF, air, stainless steel, and glass wool.

\begin{tabular}{|c|c|c|c|c|c|}
\hline $\begin{array}{c}\text { Thermophysical } \\
\text { properties }\end{array}$ & \multicolumn{2}{|c|}{ HTF } & \multirow{2}{*}{ air } & stainless & glass \\
steel & $553 \mathrm{~K}$ & $353 \mathrm{~K}$ & & wool \\
\hline$\lambda(\mathrm{W} / \mathrm{m} \cdot \mathrm{K})$ & 0.1006 & 0.1146 & 0.0242 & 18 & 0.043 \\
\hline$c_{p}(\mathrm{~J} / \mathrm{kg} \cdot \mathrm{K})$ & 2380 & 1780 & 1006.43 & 502 & 750 \\
\hline$\rho\left(\mathrm{kg} / \mathrm{m}^{3}\right)$ & 849 & 966.5 & 0.854 & 7930 & 30 \\
\hline
\end{tabular}


Three different nitrate salts, the Solar salt (60wt.\% $\mathrm{NaNO}_{3}-40 \mathrm{wt} . \%$ $\mathrm{KNO}_{3}$ ), a binary nitrates salt (46wt.\% $\left.\mathrm{NaNO}_{3}-54 \mathrm{wt} . \% \mathrm{LiNO}_{3}\right)$, and the Hitec salt (7wt.\% $\mathrm{NaNO}_{3}-40 \mathrm{wt} . \% \mathrm{NaNO}_{2}-53 \mathrm{wt} . \% \mathrm{KNO}_{3}$ ) are selected as the PCMs for PCM1, PCM2, and PCM3, respectively. The HTF is the synthetic thermal oil (Therminol 66). Table 2 lists the thermophysical properties of the salts, and Table 3 gives the thermophysical properties of the HTF, air, stainless steel, and glass wool.

\subsection{Numerical Model}

Three assumptions are applied to develop the mathematical model: (a) the flow is incompressible, (b) natural convection of the liquid PCMs during the melting and solidification processes are considered by operating the Boussinesq approximation, (c) the heat transfer of the air in the heat exchangers is controlled only by thermal conduction.

The governing equations for the continuity, momentum and energy conservations in the thermal oil flow are:

$\nabla \cdot u_{f}=0$

$\frac{\partial u_{f}}{\partial t}+u_{f} \cdot \nabla u_{f}=g-\frac{\nabla p}{\rho_{f}}+\frac{\eta_{f}}{\rho_{f}} \nabla^{2} u_{f}$

$\rho_{f} c_{p, f}\left(\frac{\partial T}{\partial t}+u_{f} \cdot \nabla T\right)=\lambda_{f} \nabla^{2} T$

where $u_{f}$ is the velocity of the HTF, $\rho_{f}$ is the HTF's density, $g$ is the gravitational acceleration, $t$ is the time, $p$ is the pressure, $\eta_{f}$ is the dynamic viscosity of the HTF, $\lambda_{f}$ is the thermal conductivity of the HTF, and $c_{p}$ is the specific heat capacity of the HTF.

Based on the above assumptions, the governing equations of the PCMs and the air are listed as follows.

Continuity equation:

$\nabla \cdot u_{p c m}=0$

where $u_{p c m}$ is the flow velocity of the PCMs.

Momentum equation of the PCMs:

$$
\begin{gathered}
\rho_{p c m} \frac{\partial\left(u_{p c m}\right)}{\partial t}+\rho_{p c m} u_{p c m} \cdot \nabla\left(u_{p c m}\right) \\
=\rho_{r e f}\left(1-\beta\left(\mathrm{T}_{p c m}-\mathrm{T}_{r e f}\right)\right) g-\nabla p \\
\quad+\eta_{p c m} \nabla^{2} u_{p c m}+\frac{(1-\gamma)^{2}}{\varepsilon+\gamma^{3}} A_{m u s h} u_{p c m}
\end{gathered}
$$

where $\rho_{p c m}$ is the density of the PCMs, $\rho_{\text {ref }}$ is the reference density at the reference temperature $T_{r e f}, \eta_{p c m}$ is the dynamic viscosity of the PCMs, the mushy zone constant Amush is set to be $10^{5} \mathrm{~kg} / \mathrm{m}^{3} \cdot \mathrm{s}$, a small parameter $\varepsilon$ is 0.001 , and $\gamma$ is the liquid fraction. The liquid fraction can be calculated by:

$$
\gamma= \begin{cases}1 & T \geq T_{l} \\ \frac{T-T_{s}}{T_{l}-T_{s}} & T_{s}<T<T_{l} \\ 0 & T \leq T_{s}\end{cases}
$$

where $T_{l}$ and $T_{s}$ are the liquidus and solidus temperature of the PCMs, respectively.

Energy equation of the PCMs:

$\rho_{p c m} \frac{\partial H}{\partial t}+\nabla \cdot\left(\rho_{p c m} u_{p c m} H\right)=\nabla \cdot\left(\lambda_{p c m} \nabla T\right)$

where the total enthalpy $H$ is defined as:

$H=h+\Delta H$

The sensible enthalpy $h$ can be calculated by:

$h=h_{0}+\int_{T_{0}}^{T} c_{p, p c m} d T$
$\Delta H=\gamma \times L$

where $\lambda_{p c m}$ is the thermal conductivity of the PCMs, $h_{0}$ is the initial enthalpy, $c_{p, p c m}$ is the specific heat capacity of the PCMs, $\Delta H$ is the latent heat content of the PCMs, and $L$ is the heat of fusion.

Energy equation of the air:

$\rho_{a} c_{p, a} \frac{\partial T}{\partial t}=\lambda_{a} \nabla^{2} T$

where $\rho_{a}, c_{p, a}, \lambda_{a}$ is the density, specific heat capacity and thermal conductivity of the air, respectively.

Energy equation of the solid tubes and shells:

$\rho_{s} c_{p, s} \frac{\partial T}{\partial t}=\lambda_{s} \nabla^{2} T$

where $\rho_{s}, c_{p, s}, \lambda_{s}$ is the density, specific heat capacity and thermal conductivity of the solid tubes and shells, respectively.

Boundary conditions:

The outer wall of the thermal insulation material is assumed to the convection condition with a heat transfer coefficient of $8 \mathrm{~W} / \mathrm{m} \cdot \mathrm{K}$ and the surrounding temperature of $298 \mathrm{~K}$. The inlet is set as the velocityinlet, and the outlet is set as the outflow.

Initial conditions:

During the charging process, $t=0, T_{p c m}=T_{\text {tube }}=298 \mathrm{~K}, T_{f}=T_{\text {inlet }}$.

During the discharging process, $t=0, T_{p c m}=T_{\text {tube }}=553 \mathrm{~K}, T_{f}=T_{\text {inlet }}$.

The commercial software ANSYS Fluent v18.2 is used to simulate the melting and solidification processes of the PCMs. The flow of thermal oil is fully turbulent, and thus standard $\mathrm{k}-\varepsilon$ turbulence model is adopted. In the Fluent's solver settings, the scheme is selected as the SIMPLE. The discrete formats of the momentum and the energy equation are both second-order upwind, and the discrete format of the pressure is PRESTO! method. The under-relaxation factors for pressure, momentum, energy, and liquid fraction are set to $0.15,0.15,0.2$, and 0.9 , respectively. As for the residual monitors, the absolute criterion of the energy equation is $10^{-8}$, and the absolute criteria of the continuity and velocity equations are $10^{-3}$.

In order to better investigate the dynamic thermal performance of the charging and discharging processes, several physical quantities are defined for energy analysis. The accumulated stored and released energy are defined as:

$$
\begin{aligned}
& Q_{\text {char }, j}=\int_{T_{\text {char }, 0}}^{T_{\text {ave }, j}} m_{j} c_{p, j} d T+m_{j} \gamma_{\text {ave }, j} L_{j} \\
& Q_{\text {dischar }, j}=\int_{T_{\text {ave }, j}}^{T_{\text {dischar }, 0}} m_{j} c_{p, j} d T+m_{j} \gamma_{\text {ave }, j} L_{j}
\end{aligned}
$$

where $j$ is the stage number of the PCMs with the range of 1-3, $T_{a v e, j}$ is the mass-average temperature of the $j$ th PCM, $\gamma_{a v e, j}$ is the volumeaverage liquid fraction of the $j$ th $\mathrm{PCM}, c_{p, j}$ is the specific thermal capacity of the $j$ th PCM, and $m_{j}$ is the mass of the $j$ th PCM. The average charging and discharging powers of the PCMs are given as:

$$
\begin{aligned}
& P_{\text {ave }, \text { char }, j}=\frac{E_{\text {char }, j}}{\tau_{\text {char }}} \\
& P_{\text {ave }, \text { dischar }, j}=\frac{E_{\text {dischar }, j}}{\tau_{\text {dischar }}}
\end{aligned}
$$

where $\tau_{\text {char }}$ is the fully charging time when the solid PCMs melt completely during the charging process, $E_{c h a r, j}$ is the total stored energy of the $j$ th PCM at the time $\tau_{\text {char }}, \tau_{\text {dischar }}$ is the fully discharging time when the liquid PCMs solidify completely and $E_{d i s c h a r, j}$ is total released energy of the $j$ th PCM at the time $\tau_{\text {dischar }}$.

Three different grids (310554, 347240, and 445693 elements) and three different time-steps $(0.05,0.1$, and $0.15 \mathrm{~s})$ are used to check the grid and time-step independence. The relative errors of different grids and time-steps are listed in Table 4, which show that the grid of 347240 elements and the time-step of $0.1 \mathrm{~s}$ satisfy the independence requirements. 
Table 4 The relative errors of different grids and time-steps.

\begin{tabular}{|c|c|c|c|c|}
\hline & $\begin{array}{c}\text { Cell } \\
\text { elements }\end{array}$ & $\begin{array}{c}\text { Time- } \\
\text { steps (s) }\end{array}$ & $\begin{array}{c}\text { Melting } \\
\text { times of } \\
\text { PCM3 (min) }\end{array}$ & $\begin{array}{c}\text { Relative } \\
\text { errors }\end{array}$ \\
\hline \multirow{3}{*}{$\begin{array}{c}\text { Grid } \\
\text { independence }\end{array}$} & 310554 & \multirow{3}{*}{0.1} & 90.0 & $2.33 \%$ \\
\hline & 347240 & & 92.2 & - \\
\hline & 445693 & & 92.4 & $0.25 \%$ \\
\hline \multirow{3}{*}{$\begin{array}{l}\text { Time-step } \\
\text { independence }\end{array}$} & \multirow{3}{*}{347240} & 0.05 & 92.5 & $0.33 \%$ \\
\hline & & 0.1 & 92.2 & - \\
\hline & & 0.15 & 92.1 & $0.09 \%$ \\
\hline
\end{tabular}

\subsection{Model Validation}

To validate the numerical model, the above model is used to simulate an experiment presented in Longeon et al. (2013) with the same boundary and initial conditions. In that reported experiment, hot water was used to charge a one-stage shell-and-tube latent heat storage unit filled with paraffin RT35. As shown in Fig. 3, the average temperature of PCM predicted by the above model agree well with the experimental data. Therefore, the present model can be used to simulate the melting and solidification processes of the PCMs in the shell-and-tube heat exchanger.

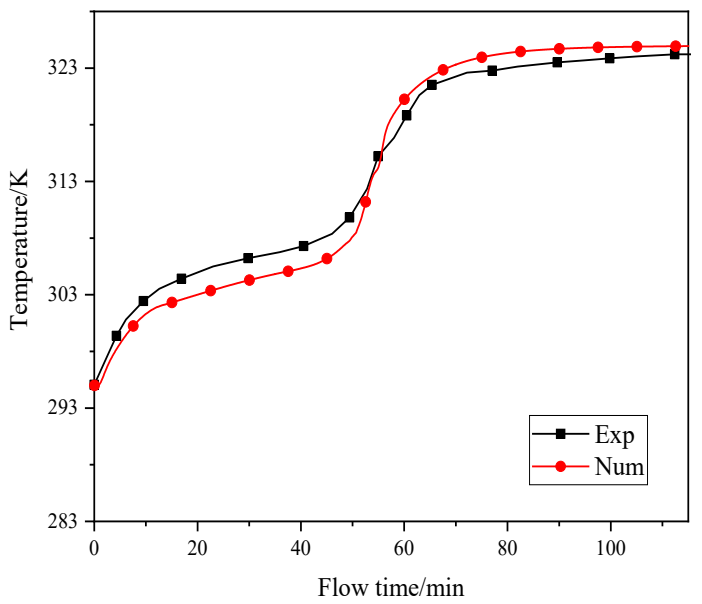

Fig. 3 Comparison of the predicted temperature variation with the present numerical model (Num.) and the experimental data (Exp.).

\section{RESULTS AND DISCUSSION}

The fully charging and discharging processes of the proposed LHTES unit are simulated by the above numerical model. The dynamical thermal performance of the charging and discharging processes is analyzed. The evolutions of liquid fraction, temperature, and thermal energy transfer are discussed. Moreover, the effects of the HTF inlet temperature on the cascaded system are studied.

\subsection{Fully Charging Process}

A typical charging case with an inlet temperature of $553 \mathrm{~K}$ and a volume flow rate of $1.0 \mathrm{~m}^{3} / \mathrm{h}$ is calculated in this subsection. Fig. 4 shows the contours of liquid fractions and temperatures for PCM1PCM3 during the charging process. From Fig. 4a, PCM3 melts fastest because of its lowest melting temperature, and then PCM2 and PCM1. Due to natural convection, the melted PCMs flow upward, resulting in the PCMs at the top fully melt first. Thus, the high-temperature zone of all three PCMs expands downward. At $2.0 \mathrm{~h}$, PCM3 has completely molten, while about $52 \%$ of PCM 2 and $23 \%$ of PCM 1 melt, respectively. At the moment, the mass-average temperatures of PCM1, PCM2, and PCM 3 are $527 \mathrm{~K}, 538 \mathrm{~K}$ and $549 \mathrm{~K}$, respectively, as shown in Fig. 4b. Therefore, for the cascaded LHTES system, the melting rate of each stage mainly depends on the melting temperature of PCM during the charging process.
Figure 5 presents the evolution of the volume-average liquid fractions $\left(\gamma_{\text {avel }}, \gamma_{\text {ave } 2}\right.$, and $\left.\gamma_{\text {ave } 3}\right)$ and mass-average temperatures $\left(T_{\text {avel }}\right.$, $T_{\text {ave } 2}$, and $\left.T_{\text {ave } 3}\right)$ of PCM1, PCM2 and PCM3 during the charging process. From Fig. $5 \mathrm{~b}$, the increases of $T_{\text {avel }}, T_{\text {ave } 2}$, and $T_{\text {ave } 3}$ slow down during the charging process. This is because the temperature differences between the HTF and the PCMs decrease. At $360 \mathrm{~min}, T_{\text {avel }}, T_{\text {ave } 2 \text {, and }}$ $T_{\text {ave } 3}$ are $543 \mathrm{~K}, 548 \mathrm{~K}$, and $551 \mathrm{~K}$, respectively, which approach the HTF inlet temperature $(553 \mathrm{~K})$. On the other hand, $\gamma_{\text {avel }}, \gamma_{\text {ave } 2}$, and $\gamma_{\text {ave } 3}$ show quite different trends. $\gamma_{\text {ave } 3}$ almost linearly increases from 0 to 1 . $\gamma_{\text {avel }}$ and $\gamma_{\text {ave } 2}$ first linearly increase, then accelerate, and finally decelerate to 1 . The acceleration of $\gamma_{\text {avel }}$ and $\gamma_{\text {ave } 2}$ raises because more and more heat is used to melt the PCMs as $T_{\text {ave } 1}$ and $T_{\text {ave } 2}$ increase. After $253 \mathrm{~min}$ and $158 \mathrm{~min}$ for PCM1 and PCM2, respectively, the temperature differences between the PCMs and the HTF are significantly reduced, resulting in a decrease of the charging rates. Accordingly, the increases of $\gamma_{\text {avel }}$ and $\gamma_{\text {ave } 2}$ decelerate. The fully melting times of PCM1-PCM3 are 332, 235, and 92 min, respectively.

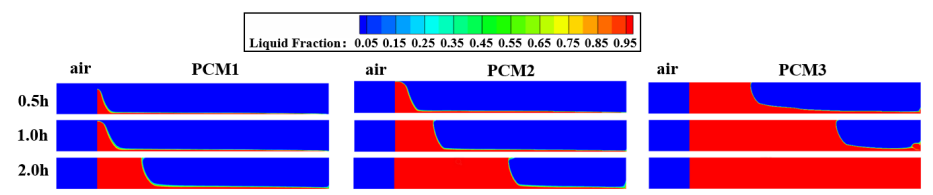

(a)

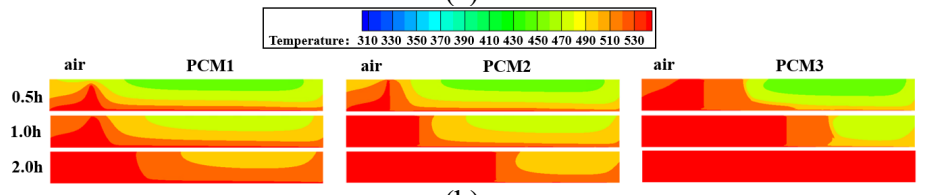

(b)

Fig. 4 The contours of (a) liquid fraction and (b) temperature for PCM1, PCM2 and PCM3 during the charging process.

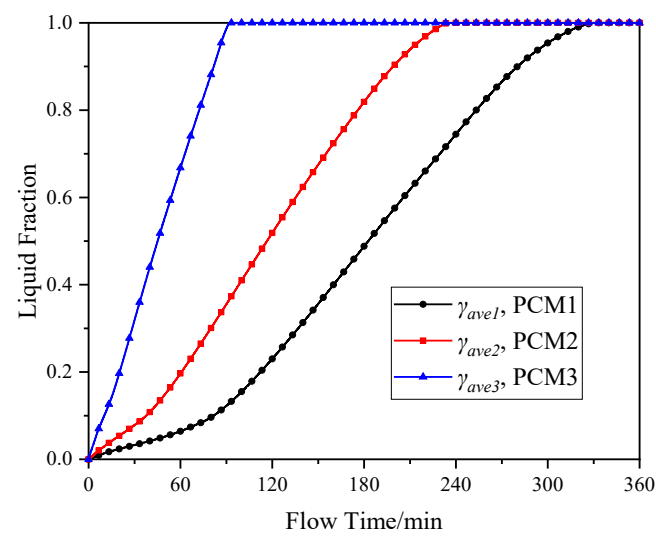

(a)

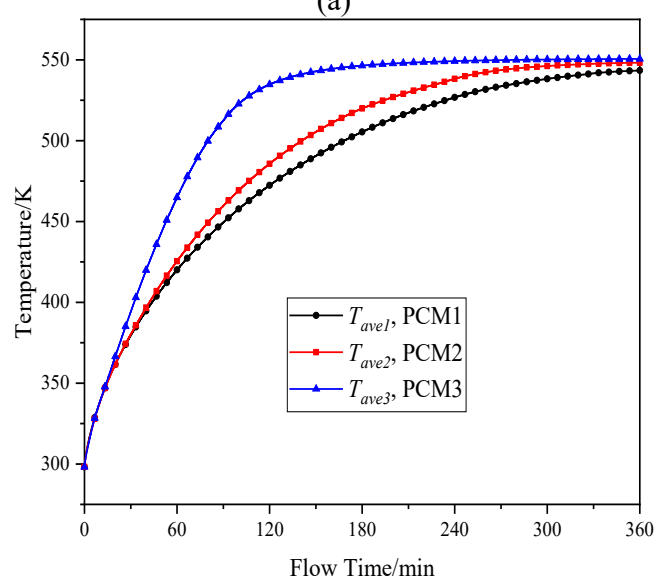

(b)

Fig. 5 The evolution curves of PCMs during the charging process: (a) volume-average liquid fractions, (b) mass-average temperatures. 
Figure 6 presents the evolution of the outlet HTF temperature and the total charging rate of the LHTES unit during the charging process. From Fig. 6, the total charging rate drops from a very high value to $2045 \mathrm{~W}$ and the outlet HTF temperature rises sharply from a low value to $549 \mathrm{~K}$ in the initial 10 minutes. From 10 to $110 \mathrm{~min}$, the PCMs' temperatures continually ascend, and thus the temperature differences between the HTF and the PCMs decrease. Thereby the charging rate decelerates. After $110 \mathrm{~min}$, most PCMs have melted, the heat transfer rate further declines with the increasing temperatures of PCMs. Finally, the heat transfer rate decreases to about zero and the HTF outlet temperature gradually rises to about $553 \mathrm{~K}$.

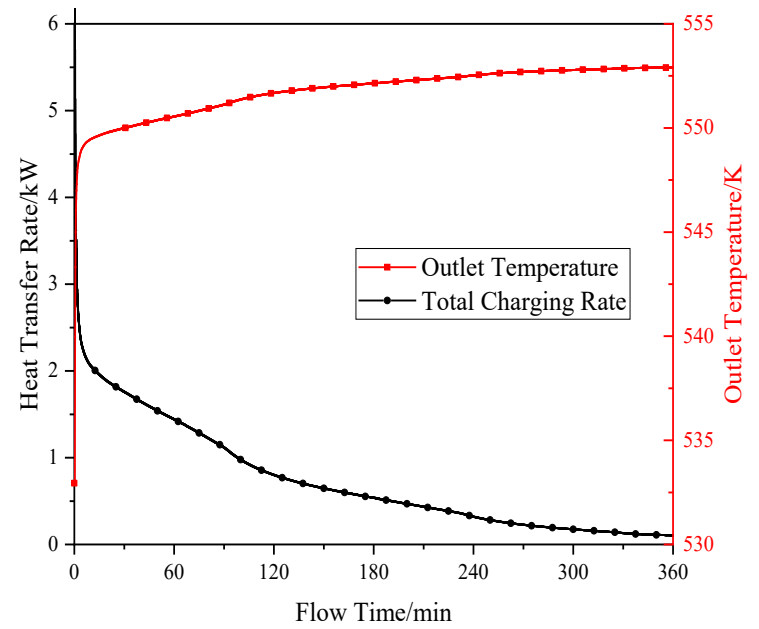

Fig. 6 The evolution curves of the outlet HTF temperature and the total charging rate between the HTF and the PCMs with time.

Figure 7 demonstrates the time-varying curves of the accumulated stored energy of PCM1, PCM2 and PCM3 during the charging process. As shown in Fig. 7, PCM2 possesses the highest heat storage capacity of 5.0 MJ, while PCM3 has the lowest heat storage capacity of $3.1 \mathrm{MJ}$, and total heat storage capacity of PCM1 is about 3.4 MJ. The highest latent heat of PCM2 $(250.1 \mathrm{~J} / \mathrm{g})$ leads to its highest heat storage capacity, in contrast, the lowest latent heat of PCM3 $(51.63 \mathrm{~J} / \mathrm{g})$ contributes to its lowest heat storage capacity. Consequently, PCMs with high latent heat should be selected in practical applications of LHTES unit to store more thermal energy.

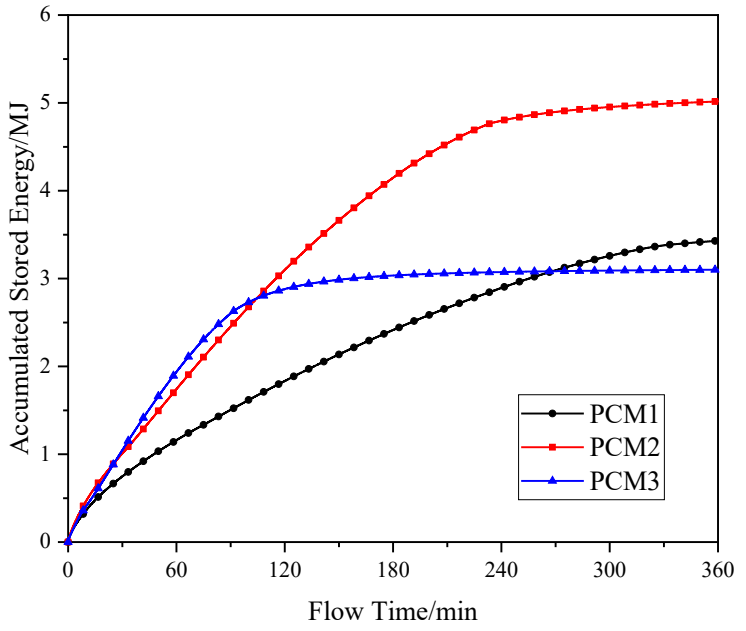

Fig. 7 The evolution curves of the accumulated stored energy of the PCMs during the charging process.

Based on the above results, it can be seen that PCM3 has the largest charging power and the fastest melting rate due to its lowest melting temperature and minimum latent heat as shown in Table 2. However, even though $L_{2}$ is much larger than $L_{1}$, PCM2 still melts faster than PCM1, which indicates the lower melting temperature of PCM2 significantly accelerates its melting rate. It can be referred that the deep-rooted reason of this phenomenon is the larger natural convection of PCM2 caused by its lower melting temperature. Therefore, in practical application, to speed up the melting process, the PCM with higher latent heat and lower melting temperature concurrently is a better choice. Besides, compared with the noncascaded LHTES, part of PCM of the cascaded LHTES can use the PCM with a lower melting temperature and a larger latent heat to enhance the charging performance.

\subsection{Fully Discharging Process}

In order to discuss the typical discharging performance of the arranged unit, the cold HTF with a temperature of $353 \mathrm{~K}$ and a volume flow rate of $3.4 \mathrm{~m}^{3} / \mathrm{h}$ flows through PCM3, PCM2, and PCM1 successively.

Figure 8 presents the change of the contours of liquid fractions and temperatures during the discharging process. From Fig. 8a, due to the highest solidification temperature, PCM1 solidifies fastest. The bottom PCMs and the PCMs close to the inner pipe are easier to solidify. At 2.0 h, PCM1 has almost completely solidified, while $74 \%$ of PCM2 and $79 \%$ of PCM3 solidify. At the moment, the mass-average temperatures of PCM1, PCM2 and PCM3 drop to $395 \mathrm{~K}, 399 \mathrm{~K}$ and $375 \mathrm{~K}$, respectively. From Fig. 8b, due to flow direction of $\mathrm{HTF}$, the temperature of PCM3 decrease the most, and PCM2, and then PCM1. The low-temperature zones of the three PCMs expand upward from the bottom and outward from tube side. Since the metal shells are cooled down by the HTF very quick, the air in contact with the metal shells is also cooled down faster than the air in contact with the PCMs. Besides, due to much lower density and heat capacity of air, the air temperatures drop faster than PCMs, which results in the raise of the temperature differences between PCMs and air.

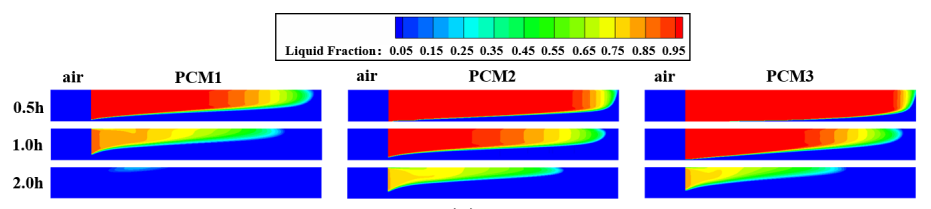

(a)

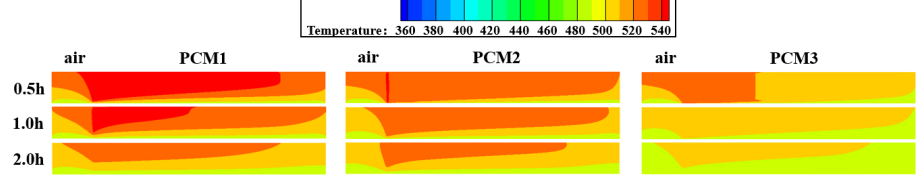

(b)

Fig. 8 The contours of (a) liquid fraction and (b) temperature for PCM1, PCM2, and PCM3 during the discharging process.

Figure 9 shows the evolution of volume-average solidification fractions ( $\varphi_{\text {avel }}, \varphi_{\text {ave } 2}$, and $\left.\varphi_{\text {ave } 3}\right)$ and mass-average temperatures of PCM1, PCM2, and PCM3 ( $T_{a v e l}, T_{a v e 2}$, and $\left.T_{a v e 3}\right)$, respectively, during the discharging process. From Fig. 9, $T_{\text {ave } 1}, T_{a v e 2}$, and $T_{\text {ave } 3}$ decrease to their freezing points with different rates due to the flow direction of HTF: $T_{\text {ave } 3}$ is the fastest, and then $T_{\text {ave } 2}$ and $T_{\text {avel }}$. With more and more PCMs solidify, the increase rates of $\varphi_{\text {avel }}, \varphi_{\text {ave2 }}$, and $\varphi_{\text {ave } 3}$ raise firstly. At $17 \mathrm{~min}, 27 \mathrm{~min}$, and $43 \mathrm{~min}$ for PCM1, PCM2, and PCM3, respectively, $T_{a v e l}, T_{a v e 2}$, and $T_{a v e 3}$ decrease to themselves freezing points. Then decrease rates of $T_{\text {avel }}, T_{\text {ave } 2}$, and $T_{\text {ave } 3}$ significantly slow down due to the released latent heat. Thereafter, due to the smallest latent heat, $T_{\text {aves }}$ decreases fastest. Besides, in spite of the HTF flowing through PCM2 before PCM1, the decrease rates of $T_{\text {avel }}$ is greater than that of $T_{\text {ave } 2}$, which is due to that $L_{2}$ is much higher than $L_{1}$. In particular, the evolution curves of $\varphi_{\text {ave } 2}$ and $\varphi_{\text {ave }}$ intersect at $95 \mathrm{~min}$ which is also due to the fact that $L_{2}$ is much higher than $L_{3}$. After 53, 72 and $86 \mathrm{~min}$ for PCM1, PCM2 and PCM3, respectively, the increase rates of $\varphi_{\text {avel }}$, $\varphi_{\text {ave2}}$, and $\varphi_{\text {ave }}$ decrease because of the decreasing temperatures of the PCMs and their discharging heat transfer rates. Finally, the liquid fractions drop to zero when the PCMs completely solidify. Due to the 
facts that $L_{2}$ is much higher than $L_{I}$ and PCM1 fully solidify at $120 \mathrm{~min}$, $T_{\text {avel }}$ becomes lower than $T_{\text {ave2 }}$ at $147 \mathrm{~min}$. Then, PCM2 and PCM3 fully solidify at 209 , and $178 \mathrm{~min}$, respectively. At $240 \mathrm{~min}, T_{\text {avel }}, T_{\text {ave } 2}$, and $T_{\text {ave } 3}$ descend to $445 \mathrm{~K}, 438 \mathrm{~K}$, and $398 \mathrm{~K}$, respectively.

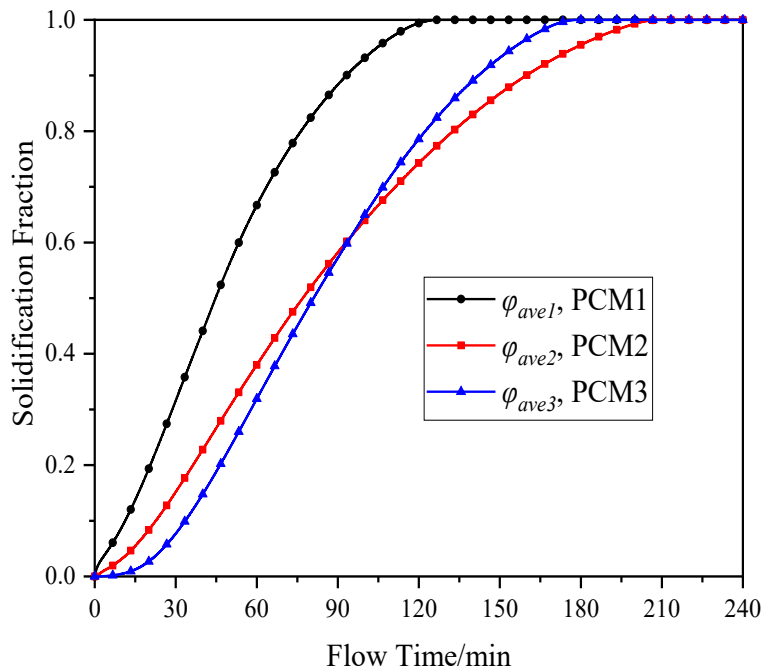

(a)

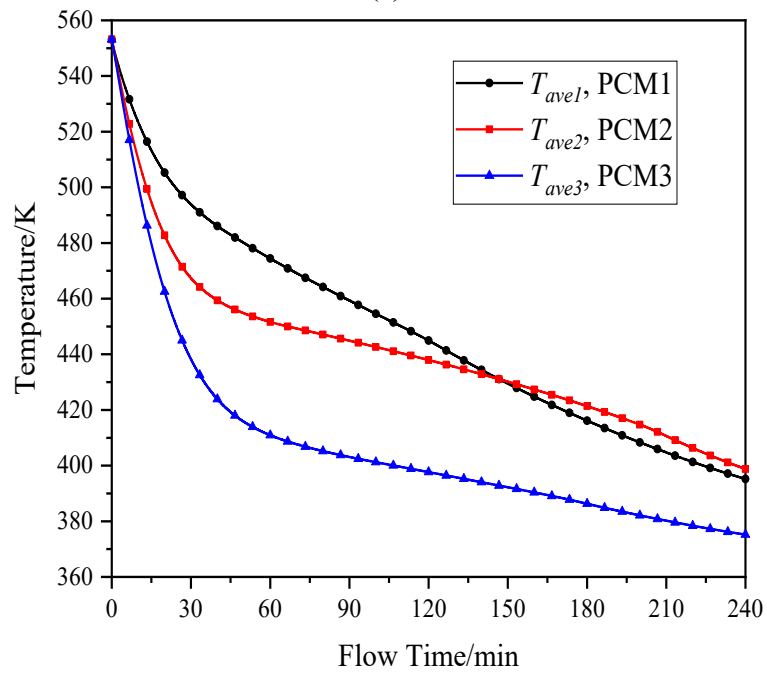

(b)

Fig. 9 The evolution of: (a) volume-average solidification fractions, (b) mass-average temperatures for PCM1-PCM3 during the discharging process.

Figure 10 shows the evolution of the HTF outlet temperature and the total discharging rate between the HTF and the three PCMs during the discharging process. Similar to the charging process, the total discharging rate between the PCMs and the HTF presents a downward trend, and its decrease rate also decelerates. From Fig. 10, HTF outlet temperature decreases from a high value to $354 \mathrm{~K}$ and the total discharging rate decrease sharply from a high value to $755 \mathrm{~W}$ during the initial 60 minutes. From 60 to $240 \mathrm{~min}$, HTF outlet temperature gains a small reduction, while the total discharging rate linearly decrease from 755 to $243 \mathrm{~W}$. The variation trend of the total discharging rate also corresponds to that of the outlet temperature. The larger the discharging rate is, the more heat is transferred from the PCMs to the HTF for the same time interval, and the higher temperature the HTF possesses. Hence, after $60 \mathrm{~min}$, the HTF temperature is very low, which indicates that further measures should be taken in practical application, such as extending the length of each stage in the TES unit, so as to increase the HTF outlet temperature.

Figure 11 displays the evolution of the accumulated released energy of PCM1, PCM2, and PCM3, respectively, during the discharging process. As the decreases in $T_{a v e l}, T_{\text {ave2 }}$, and $T_{a v e 3}$, the increase rates of accumulated released energy of three PCMs decline. The accumulated released energy of PCM1 is the smallest, for PCM1 solidifies fastest because of the highest freezing temperature and lower latent heat, which leads to the largest increase of the thermal conduction resistance of the PCM so that increasing the heat release resistance, and thus reducing the discharging power. The accumulated released energy of PCM2 and PCM3 is close in the initial 75 minutes, but after 75 min, the accumulated released energy of PCM2 is higher than that of PCM3. This is because that the temperature of PCM2 decreases slowly due to its high latent heat, so that the temperature difference between the PCM and the HTF is large, and larger discharging power can be maintained for a long time. At $240 \mathrm{~min}, \mathrm{PCM} 2$ has the highest heat release capacity of 4.2 MJ, while the release capacities of PCM1 and PCM3 are 3.0 MJ and 3.4 MJ, respectively. Consequently, the above results show that the PCM with higher melting temperature releases less heat. In practical application, in order to improve the discharging performance of the PCMs with high melting temperature, on the one hand, the PCMs with high latent heat can be selected, on the other hand, PCMs with high thermal conductivity or heat transfer enhancement techniques can be utilized. Through the selection of the PCMs, the cascaded LHTES systems can possess better flexibility than the non-cascaded LHTES systems.

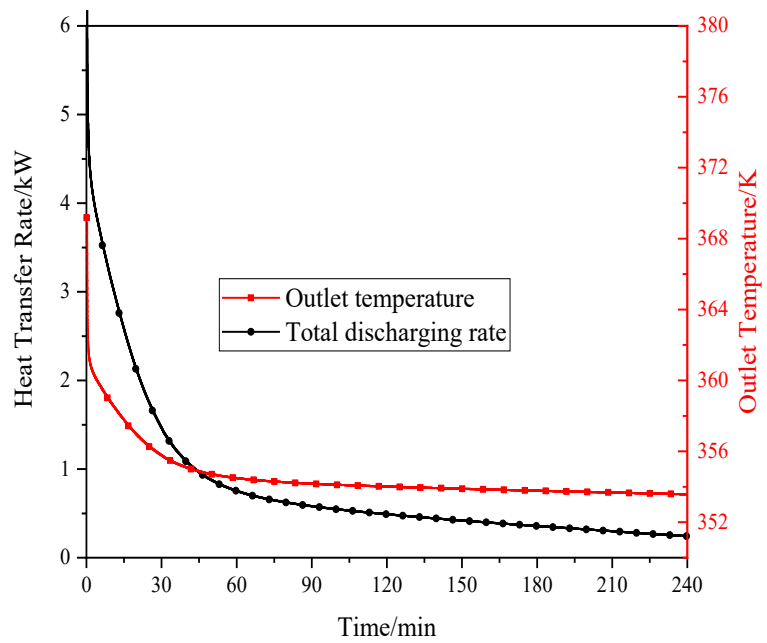

Fig. 10 The evolution of the HTF outlet temperature and the total charging rates between the HTF and the PCMs during the discharging time.

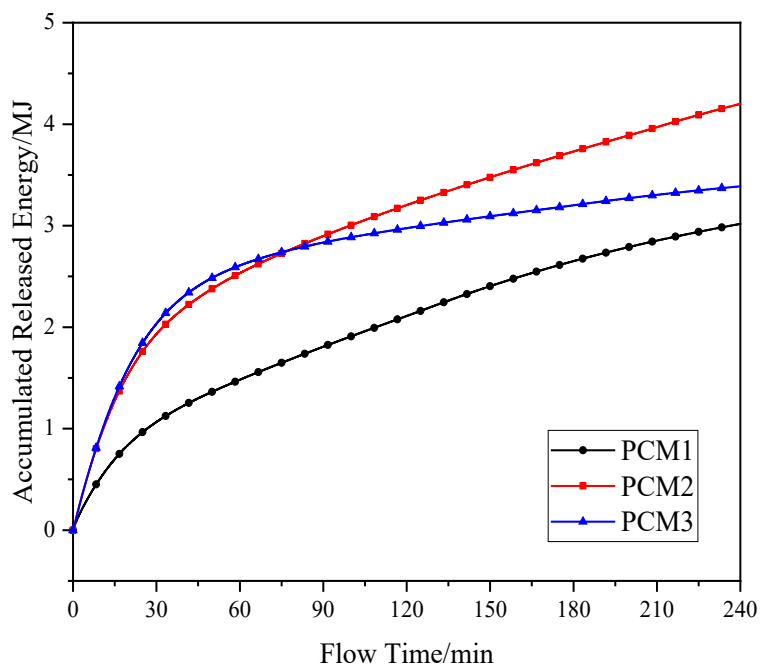

Fig. 11 The evolution of the accumulated released energy of the PCMs during the discharging process. 


\subsection{Effects of the HTF Inlet Temperature}

The effects of the HTF inlet temperature on the charging and discharging processes are investigated. The HTF inlet temperature increases from 533 to $573 \mathrm{~K}$ during the charging process and from 333 to $373 \mathrm{~K}$ during the discharging process.

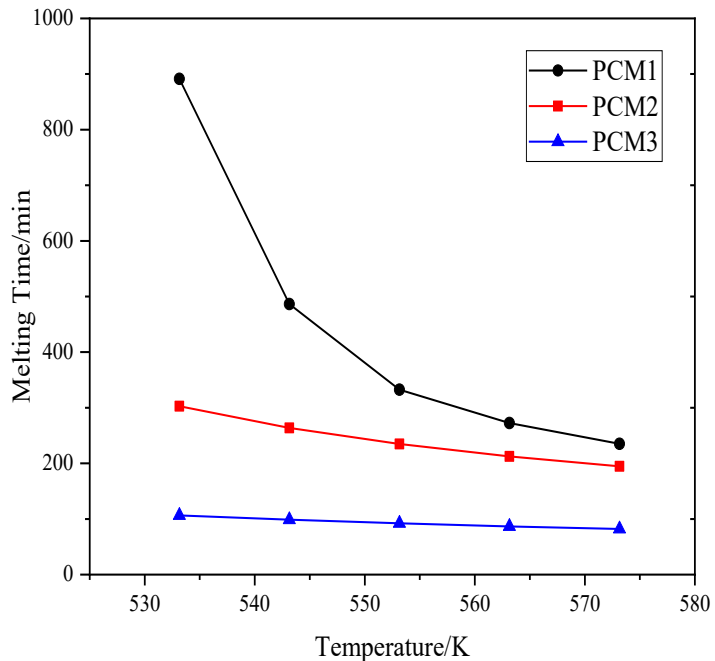

(a)

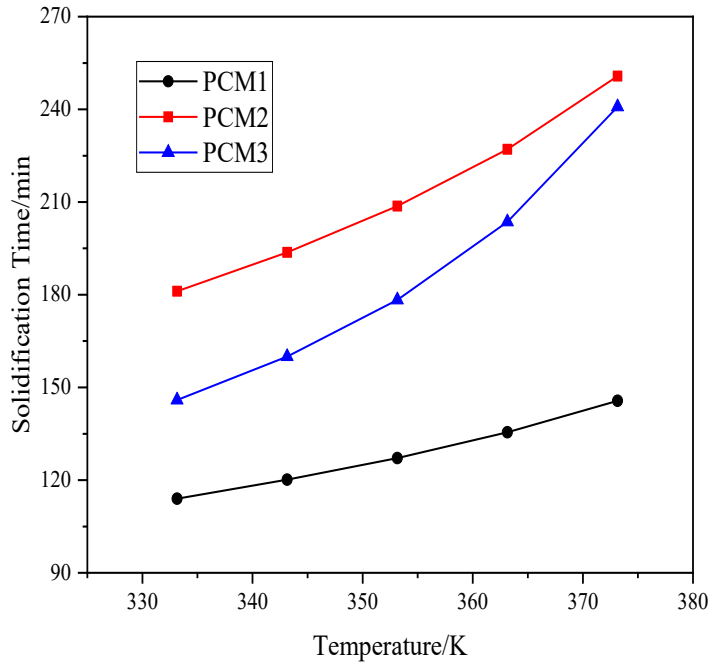

(b)

Fig. 12 The changes of the melting time during the charging process (a) and the solidification time during the discharging process (b) with different HTF inlet temperatures.

Figure 12 shows the melting and solidification times for different inlet HTF temperatures. Fig. 13 displays the average charging and discharging power as a function of inlet HTF temperature. From Figs. 12 and 13, with the HTF inlet temperature increasing from 533 to 573 $\mathrm{K}$, the melting times decrease from 891 to $235 \mathrm{~min}$, from 303 to 195 $\mathrm{min}$, and from 106 to $82 \mathrm{~min}$ for PCM1, PCM2, and PCM3, respectively, during the charging process. While the average charging powers increase from 80 to $245 \mathrm{~W}$, from 93 to $367 \mathrm{~W}$, and from 54 to $237 \mathrm{~W}$ for PCM1, PCM2, and PCM3, respectively. The melting time of PCM1 and the average charging power of PCM2 are most affected by the HTF inlet temperature. With the increase of the HTF inlet temperature from 333 to $373 \mathrm{~K}$ during the discharging process, the solidification times increase from 114 to $146 \mathrm{~min}$, from 181 to $251 \mathrm{~min}$, and from 146 to $241 \mathrm{~min}$, the average discharging powers approximately linearly decrease from 260 to $193 \mathrm{~W}$, from 365 to $264 \mathrm{~W}$, and from 309 to $215 \mathrm{~W}$, for PCM1, PCM2, and PCM3, respectively. The results can be explained by that higher inlet temperature during the charging process causes bigger temperature difference between the
HTF and the PCMs, which induces a higher heat transfer rate from the HTF to the PCMs. On the contrary, higher inlet temperature during the discharging process leads to smaller temperature differences between the HTF and the PCMs, which causes smaller heat transfer rate from the PCMs to the HTF.

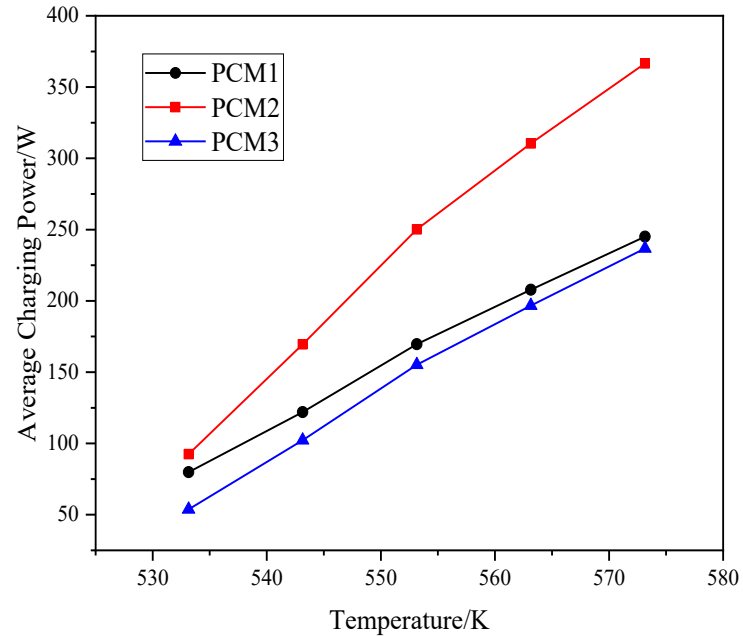

(a)

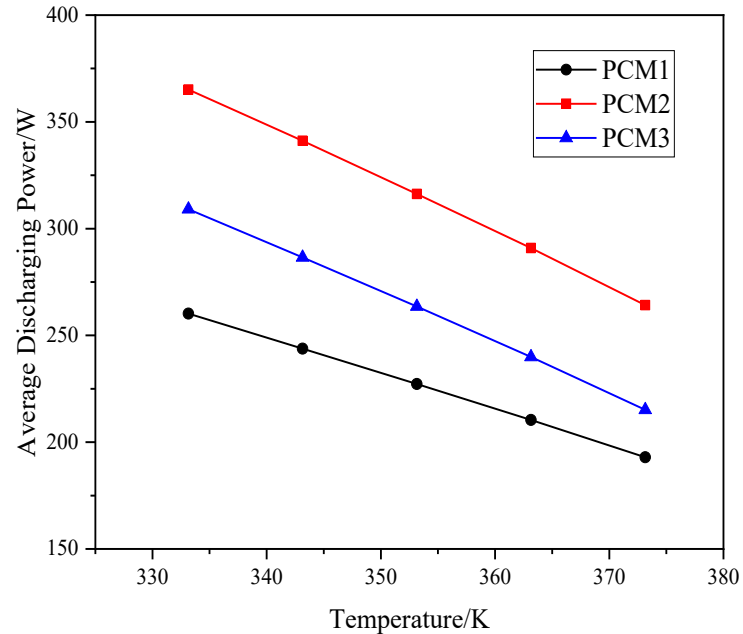

(b)

Fig. 13 The change of the average charging and discharging powers as a function of the inlet HTF temperature.

\section{CONCLUSIONS}

This study presents a transient, two-dimension model to numerically investigate the thermal behaviors for the charging and discharging processes of the molten-salt LHTES system filled with three PCMs called PCM1, PCM2, and PCM3. Numerical simulations are carried out to calculate the fully charging and discharging processes as well as the effects of the HTF inlet temperature. The following conclusions can be drawn from the above analysis:

- During the charging process, the lower melting temperature of the PCM obviously accelerates its melting rate. Hence, to quicken up the charging process in practical application, the PCM with a higher latent heat is preferable with a lower melting temperature. Moreover, compared with the noncascaded LHTES systems, part of PCM of the cascaded LHTES systems can use the PCM with a lower melting temperature and a larger latent heat to enhance the charging performance.

- During the discharging process, the PCMs with higher melting temperature releases less heat. In order to improve the discharging performance of the PCMs with high melting 
temperature in practical application, on the one hand, the PCMs with high latent heat can be selected, on the other hand, PCMs with high thermal conductivity or heat transfer enhancement techniques can be utilized. Through the selection of the PCMs, the cascaded LHTES systems can possess better flexibility than non-cascaded LHTES systems.

- The average charging powers increase from 80 to $245 \mathrm{~W}$, from 93 to $367 \mathrm{~W}$, and from 54 to $237 \mathrm{~W}$ following the increase of the HTF inlet temperature from 533 to $573 \mathrm{~K}$, and the average discharging powers approximately linearly decrease from 260 to $193 \mathrm{~W}$, from 365 to $264 \mathrm{~W}$, and from 309 to $215 \mathrm{~W}$ following the increase of the HTF inlet temperature from 333 to $373 \mathrm{~K}$, for PCM1, PCM2, and PCM3, respectively. Higher inlet temperature causes bigger temperature difference for the charging process and smaller temperature difference for the discharging process between the HTF and the PCMs, which contributes to higher charging power and lower discharging power.

\section{ACKNOWLEDGEMENTS}

This work is supported by the National Natural Science Foundation of China (No. 51706071 and No. 51776066).

\section{NOMENCLATURE}

$\begin{array}{ll}u & \text { velocity }(\mathrm{m} / \mathrm{s}) \\ c_{p} & \text { specific heat capacity }(\mathrm{J} / \mathrm{kg} \cdot \mathrm{K}) \\ p & \text { pressure }(\mathrm{Pa}) \\ P & \text { power }(\mathrm{W}) \\ g & \text { gravitational acceleration }\left(\mathrm{m} / \mathrm{s}^{2}\right) \\ t & \text { time }(\mathrm{s}) \\ T & \text { temperature }(\mathrm{K}) \\ T_{s} & \text { solidus temperature }(\mathrm{K}) \\ T_{l} & \text { liquidus temperature }(\mathrm{K}) \\ A_{\text {mush }} & \text { mushy zone constant }, 10^{5} \mathrm{~kg} / \mathrm{m}^{3} \cdot \mathrm{s} \\ H & \text { total enthalpy }(\mathrm{J} / \mathrm{kg}) \\ h & \text { sensible enthalpy }(\mathrm{J} / \mathrm{kg}) \\ \Delta H & \text { latent heat content }(\mathrm{J} / \mathrm{kg}) \\ L & \text { heat of fusion }(\mathrm{J} / \mathrm{kg}) \\ m & \text { mass }(\mathrm{kg}) \\ Q & \text { accumulated energy }(\mathrm{J}) \\ E & \text { total energy }(\mathrm{J}) \\ & \\ \text { Greek Symbols } \\ \beta & \text { thermal expansion coefficient } \\ \gamma & \text { liquid fraction } \\ \varphi & \text { solidification fraction } \\ \varepsilon & \text { a small parameter, } 0.001 \\ \rho & \text { density }\left(\mathrm{kg} / \mathrm{m}^{3}\right) \\ \lambda & \text { thermal conductivity }(\mathrm{W} / \mathrm{m} \cdot \mathrm{K}) \\ \tau & \text { fully charging and discharging times }(\mathrm{s}) \\ \text { Subscripts } & \text { initial moment } \\ O & \text { heat transfer fluid } \\ f & \text { liquid } \\ l & \text { solid } \\ s & \text { stage number of the } \mathrm{PCMs} \\ j & \text { average } \\ \text { ave } & \text { reference } \\ r e f & \text { charging process } \\ \text { char } & \text { discharging process } \\ \text { dischar } & \\ & \end{array}$

\section{REFERENCES}

Acem, Z., Lopez, J., and Barrio, E. P. D., 2010, " $\mathrm{KNO}_{3} / \mathrm{NaNO}_{3}-$ Graphite Materials for Thermal Energy Storage at High Temperature:
Part I. - Elaboration Methods and Thermal Properties," Applied Thermal Engineering, 30, 1580-1585.

http://dx.doi.org/10.1016/j.applthermaleng.2010.03.013

Al-Abidi, A. A., Mat, S., Sopian, K., Sulaiman, M. Y., and Mohammad, A. T., 2013, "Internal and External Fin Heat Transfer Enhancement Technique for Latent Heat Thermal Energy Storage in Triplex Tube Heat Exchangers," Applied Thermal Engineering, 53, 147-156. http://dx.doi.org/10.1016/j.applthermaleng.2013.01.011

Aldoss, T. K., and Rahman, M. M., 2014, "Comparison Between the Single-PCM and Multi-PCM Thermal Energy Storage Design," Energy Conversion and Management, 83, 79-87.

http://dx.doi.org/10.1016/j.enconman.2014.03.047

Alva, G., Liu, L. K., Huang, X., and Fang, G. Y., 2017, "Thermal Energy Storage Materials and Systems for Solar Energy Applications," Renewable and Sustainable Energy Reviews, 68, 693-706.

http://dx.doi.org/10.1016/j.rser.2016.10.021

Cui, Y. B., Liu, C. H., Hu, S., and Yu, X., 2011, "The Experimental Exploration of Carbon Nanofiber and Carbon Nanotube Additives on Thermal Behavior of Phase Change Materials," Solar Energy Materials and Solar Cells, 95, 1208-1212.

http://dx.doi.org/10.1016/j.solmat.2011.01.021

Cardenas, B., and Leon, N., 2013, "High Temperature Latent Heat Thermal Energy Storage: Phase Change Materials, Design Considerations and Performance Enhancement Techniques," Renewable and Sustainable Energy Reviews, 27, 724-737.

http://dx.doi.org/10.1016/j.rser.2013.07.028

Chinnapandian, M., Pandiyarajan, V., Prabhu, A., and Velraj R., 2015, "Experimental Investigation of a Cascaded Latent Heat Storage System for Diesel Engine Waste Heat Recovery," Energy Sources, Part A: Recovery, Utilization, and Environmental Effects, 37, 1308-1317. http://dx.doi.org/10.1080/15567036.2011.586974

Domański, R., and Fellah, G., 1996, "Exergy Analysis for the Evaluation of a Thermal Storage System Employing PCMS with Different Melting Temperatures," Applied Thermal Engineering, 16(11), 907-919.

http://dx.doi.org/10.1016/1359-4311(96)00003-8

Denholm, P., and Mehos, M., 2011, "Enabling Greater Penetration of Solar Power via the Use of CSP with Thermal Energy Storage," Office of Scientific and Technical Information Technical Reports. http://dx.doi.org/10.2172/1030440

Ezra, M., Kozak, Y., Dubovsky, V., and Ziskind, G., 2016, “Analysis and Optimization of Melting Temperature Span for a Multiple-PCM Latent Heat Thermal Energy Storage Unit," Applied Thermal Engineering, 93, 315-329.

http://dx.doi.org/10.1016/j.applthermaleng.2015.09.040

Hosseini, M. J., Rahimi, M., and Bahrampoury, R., 2014, "Experimental and Computational Evolution of a Shell and Tube Heat Exchanger as a PCM Thermal Storage System," International Communications in Heat and Mass Transfer, 50, 128-136. http://dx.doi.org/10.1016/j.icheatmasstransfer.2013.11.008

Hosseini, M. J., Ranjbar, A. A., Rahimi, M., and Bahrampoury, R., 2015, "Experimental and Numerical Evaluation of Longitudinally Finned Latent Heat Thermal Storage Systems," Energy and Buildings, 99, 263272.

http://dx.doi.org/10.1016/j.enbuild.2015.04.045

Iverson, B. D., Broome, S. T., Kruizenga, A. M., and Cordaro, J. G., 2012, "Thermal and Mechanical Properties of Nitrate Thermal Storage Salts in the Solid-Phase," Solar Energy, 86, 2897-2911. http://dx.doi.org/10.1016/j.solener.2012.03.011

Kalogirou, S. A., 2004, "Environmental Benefits of Domestic Solar 
Energy Systems," Energy Conversion and Management, 45, 3075-3092. http://dx.doi.org/10.1016/j.enconman.2003.12.019

Koberle, A. C., Gernaat, D. E. H. J., and Vuuren, D. P., 2015, "Assessing Current and Future Techno-Economic Potential of Concentrated Solar Power and Photovoltaic Electricity Generation," Energy, 89, 739-756.

http://dx.doi.org/10.1016/j.energy.2015.05.145

Li, Y. Q., He, Y. L., Song, H. J., Xu, C., and Wang, W.W. 2013, "Numerical Analysis and Parameters Optimization of Shell-and-Tube Heat Storage Unit using Three Phase Change Materials," Renewable Energy, 59, 92-99.

http://dx.doi.org/10.1016/j.renene.2013.03.022

Longeon, M., Soupart, A., Fourmigué, J. F., Bruch, A., and Marty, P., 2013, "Experimental and Numerical Study of Annular PCM Storage in the Presence of Natural Convection," Applied Energy, 112, 175-184. http://dx.doi.org/10.1016/j.apenergy.2013.06.007

Liu, M., Tay, N. H. S., Belusko, M., and Bruno, F., 2015, "Investigation of Cascaded Shell and Tube Latent Heat Storage Systems for Solar Tower Power Plants," Energy Procedia, 69, 913-924.

http://dx.doi.org/10.1016/j.egypro.2015.03.175

Lefebvre, D., and Tezel, F. H., 2017, “A Review of Energy Storage Technologies with a Focus on Adsorption Thermal Energy Storage Processes for Heating Applications," Renewable and Sustainable Energy Reviews, 67, 116-125.

http://dx.doi.org/10.1016/j.rser.2016.08.019

Michels, H., and Pitz-Paal, R., 2007, "Cascaded Latent Heat Storage for Parabolic Trough Solar Power Plants," Solar Energy, 81, 829-837.

http://dx.doi.org/10.1016/j.solener.2006.09.008

Mosaffa, A. H., Ferreira, C. A. I., Talati, F., and Rosen, M.A., 2013, "Thermal Performance of a Multiple PCM Thermal Storage Unit for Free Cooling," Energy Conversion and Management, 67, 1-7.

http://dx.doi.org/10.1016/j.enconman.2012.10.018

Nkwetta, D. N., and Haghighat, F., 2014, "Thermal Energy Storage with Phase Change Material-A State-of-the Art Review," Sustainable Cities and Society, 10, 87-100.

http://dx.doi.org/10.1016/j.scs.2013.05.007

Omotani, T., and Nagashima, A., 1984, "Thermal Conductivity of Molten Salts, HTS and the $\mathrm{LiNO}_{3}-\mathrm{NaNO}_{3}$ System, using a Modified Transient Hot-Wire Method," Journal of Chemical and Engineering Data, 29, 1-3.

http://dx.doi.org/10.1021/je00035a001

Orr, B., Singh, R., Akbarzadeh, A., Mochizuki, M., 2019, "Operating Characteristics of Naphthalene Heat Pipe," Frontiers in Heat and Mass Transfer, 13.

http://dx.doi.org/10.5098/hmt.13.8

Peiró, G., Gasia, J., Miró, L., and Cabeza, L. F., 2015, "Experimental Evaluation at Pilot Plant Scale of Multiple PCMs (Cascaded) vs. Single PCM Configuration for Thermal Energy Storage," Renewable Energy, 83, 729-736.

http://dx.doi.org/10.1016/j.renene.2015.05.029

Singh, R., Mochizuki, M., Mashiko, K., Nguyen, T., 2019, "Data Center Energy Conservation by Heat Pipe Based Pre-Cooler System," Frontiers in Heat and Mass Transfer, 13.

http://dx.doi.org/10.5098/hmt.13.24

Seeniraj, R. V., and Narasimhan, N. L., 2008, "Performance Enhancement of a Solar Dynamic LHTS Module having Both Fins and Multiple PCMs," Solar Energy, 82, 535-542.

http://dx.doi.org/10.1016/j.solener.2007.11.001

Sioshansi, R., and Denholm, P., 2010, "The Value of Concentrating
Solar Power and Thermal Energy Storage," IEEE Transactions on Sustainable Energy, 1(3), 173-183.

http://dx.doi.org10.1109/TSTE.2010.2052078

Shabgard, H., Robak, C. W., Bergman, T. L., and Faghri, A., 2012, "Heat Transfer and Exergy Analysis of Cascaded Latent Heat Storage with Gravity-Assisted Heat Pipes for Concentrating Solar Power Applications," Solar Energy, 86, 816-830.

http://dx.doi.org/10.1016/j.solener.2011.12.008

Shabgard, H, Bergman, T. L., Sharifi, N., and Faghri, A., 2010, "High temperature latent heat thermal energy storage using heat pipes," International Journal of Heat and Mass Transfer, 53(15-16):2979-2988. http://doi.org/10.1016/j.ijheatmasstransfer.2010.03.035

Shabgard, H., and Faghri, A., 2019, "Exergy Analysis in Energy Systems: Fundamentals and Application," Frontiers in Heat and Mass Transfer, 12.

http://dx.doi.org/10.5098/hmt.12.9

Serrano-López, R., Fradera, J., and Cuesta-López, S., 2013, "Molten Salts Database for Energy Applications," Chemical Engineering and Processing Process Intensification, 73, 87-102.

http://dx.doi.org/10.1016/j.cep.2013.07.008

Vyshak, N. R., and Jilani, G., 2007, "Numerical Analysis of Latent Heat Thermal Energy Storage System," Energy Conversion and Management, 48, 2161-2168.

http://dx.doi.org/10.1016/i.enconman.2006.12.013

Wu, M., Xu, C., and He, Y. L., 2016, "Cyclic Behaviors of the MoltenSalt Packed-Bed Thermal Storage System Filled with Cascaded Phase Change Material Capsules," Applied Thermal Engineering, 93, 10611073.

http://dx.doi.org/10.1016/j.applthermaleng.2015.10.014

Xu, Y., He, Y. L., Li, Y. Q., and Song H. J., 2016, "Exergy Analysis and Optimization of Charging-Discharging Processes of Latent Heat Thermal Energy Storage System with Three Phase Change Materials," Solar Energy, 123, 206-216.

http://dx.doi.org/10.1016/j.solener.2015.09.021

Xu, H. J., and Zhao, C. Y., 2017, "Thermal Performance of Cascaded Thermal Storage with Phase-Change Materials (PCMs). Part I: Steady Cases," International Journal of Heat and Mass Transfer, 106, 932-944. http://dx.doi.org/10.1016/j.ijheatmasstransfer.2016.10.054

Xu, H. J., and Zhao, C. Y., 2017, “Thermal Performance of Cascaded Thermal Storage with Phase-Change Materials (PCMs). Part II: Unsteady Cases," International Journal of Heat and Mass Transfer, 106, 945-957.

http://dx.doi.org/10.1016/j.ijheatmasstransfer.2016.10.066

Yuan, F., Li, M. J., Ma, Z., Jin, B., and Liu, Z. B., 2018, “Experimental Study on Thermal Performance of High-Temperature Molten Salt Cascaded Latent Heat Thermal Energy Storage System," International Journal of Heat and Mass Transfer, 118, 997-1011.

http://dx.doi.org/10.1016/j.ijheatmasstransfer.2017.11.024

Ndlovu, P. L., and Moitsheki R. J., 2019, "Thermal Analysis of Natural Convection and Radiation Heat Transfer in Moving Porous Fins," Frontiers in Heat and Mass Transfer, 12. http://dx.doi.org/ 10.5098/hmt.12.7

Zhou, D., and Eames, P., 2016, "Thermal Characterization of Binary Sodium/Lithium Nitrate Salts for Latent Heat Storage at Medium Temperatures," Solar Energy Materials and Solar Cells, 157, 10191025 .

http://dx.doi.org/10.1016/j.solmat.2016.08.017

Zhang, Z. L., Yuan, Y. P., Alelyani, S., Cao, X. L., and Phelan, P. E., 2017, "Thermophysical Properties Enhancement of Ternary Carbonates 
Frontiers in Heat and Mass Transfer (FHMT), 15, 10 (2020)

with Carbon Materials for High-Temperature Thermal Energy Storage," Solar Energy, 155, 661-669.

http://dx.doi.org/10.1016/j.solener.2017.07.010 